\title{
Chronic Subdural Hematoma in Elderly People: Present Status on Awaji Island and Epidemiological Prospect
}

\author{
Hiroshi Kudo, Keiichi Kuwamura, Ichirou IZAwA, Hideki SAWA \\ and Norihiko TAMAKI*
}

Department of Neurosurgery, Hyogo Prefectural A waji Hospital, Sumoto, Hyogo;
${ }^{*}$ Department of Neurosurgery, Kobe University School of Medicine, Kobe

\begin{abstract}
The epidemiological aspect of chronic subdural hematoma (CSH) in the elderly who are 65 years old or elder was evaluated on Awaji Island with about 170,000 inhabitants. The overall incidence of CSH was 13.1 per 100,000 year, 3.4 in people under 65 years old, and 58.1 in the elderly. The elderly were $17.7 \%$ of all inhabitants. If these incidences of $\mathrm{CSH}$ are extrapolated to all of Japan in the year 2020 , the incidence will be 16.3 per 100,000 /year. This suggests that CSH may become the most common neurosurgical condition.
\end{abstract}

Key words: chronic subdural hematoma, aged people, epidemiology

\section{Introduction}

Chronic subdural hematoma (CSH) occurs especially frequently among old people. ${ }^{1,3 y}$ The number of old people is increasing steadily in Japan. A Ministry of Health and Welfare Survey found that the elderly who are 65 years old or elder accounted for $11.2 \%$ of all people in $1988 .{ }^{27}$ In 2020 , the population of Japan will be $135,304,000$, of which $23.6 \%$ will be the elderly. ${ }^{2)}$ Awaji Island in Hyogo prefecture presently has a population of 168,000 , of which $17.7 \%$ is the elderly. We investigated the present incidence of $\mathrm{CSH}$ on Awaji Island and discuss the epidemiological problems.

\section{Clinical Materials and Methods}

Sixty-six patients (54 males and 12 females) with CSH were admitted to our institute from January, 1986 through December, 1988. Fifty-two patients (43 males and 9 females) were the elderly. The incidences of $\mathrm{CSH}$ in the towns and city on Awaji Island were calculated to assess the epidemiological trends.

Received December 17, 1990; Accepted June 13, 1991

\section{Results}

Awaji Island consists of one city (Sumoto) and ten towns. The incidence of CSH per 100,000/ycar in the elderly ranged from 8.6 to 153.5 , with a mean of 58.1. Figure 1 shows that some areas (the towns of Goshiki and Ichinomiya) colored pink had high incidences, while areas in yellow (the towns of Awaji, Hokutan, Higashiura, Seitan, and Nantan) had low incidences. Fourteen patients under 65 years old were treated for $\mathrm{CSH}$ at our hospital. The incidence of CSH patients under 65 years old was a mean of 3.4 per $100,000 /$ year. The total incidence of $\mathrm{CSH}$ was a mean of 13.1 ranging from 4.0 to 36.1 per $100,000 /$ year (Fig. 2). The mean was 13.6 in the green areas (the towns of Tsuna, Midori, and Mihara, and Sumoto city) and 34.0 in the pink areas. The elderly were $33-100 \%$ (mean, $79 \%$ ) of all cases. The population contains $21.4 \%$ elderly in the pink areas and $15.8 \%$ in the green areas.

The epidemiological trends can be assessed, if the incidences of CSH on Awaji Island are applied to Japan until the year 2020. The incidence of CSH in the elderly as a part of the total population will be: $58.1 \times 23.6 / 100=13.7$ per $100,000 /$ ycar. The incidence of $\mathrm{CSH}$ in people under 65 years old in the total population will be: $3.4 \times 76.4 / 100=2.6$ per 


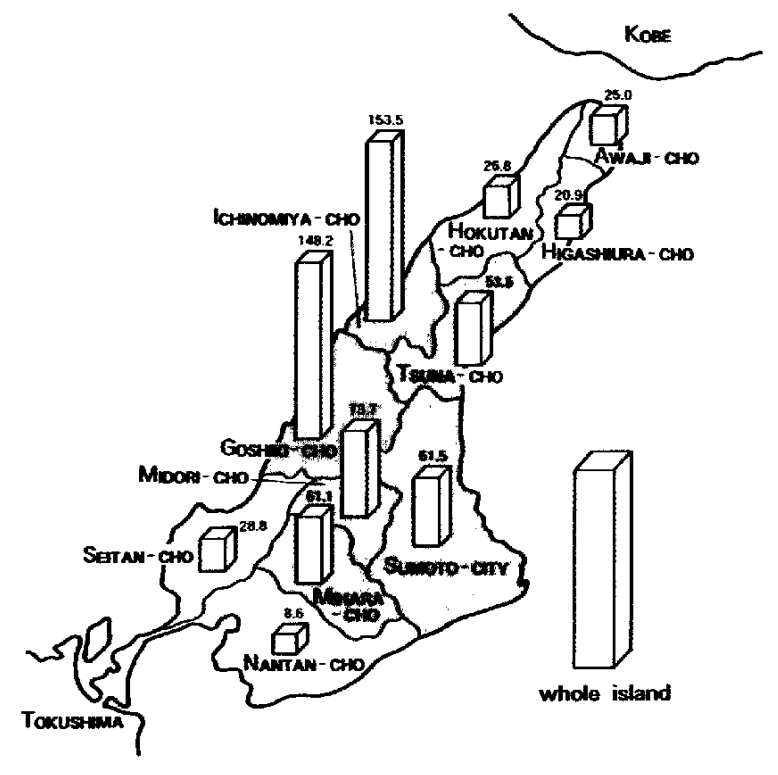

Fig. I Incidences of CSH in the elderly who are 65 years old or elder on Awaji Island $(/ 100,000$ people/yr).

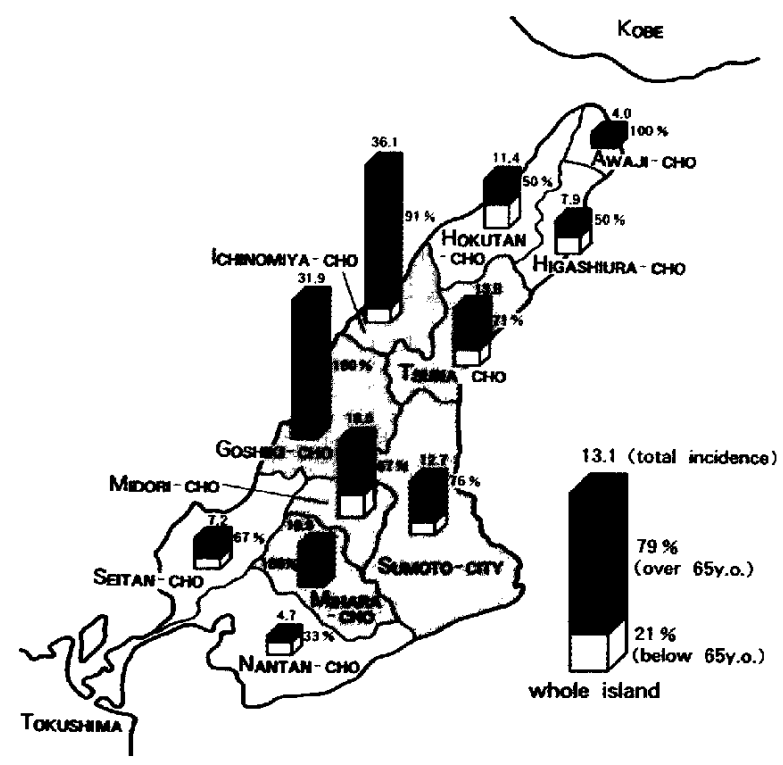

lig. 2 Incidences of $\mathrm{CSH}$ in total population on Awaji Island $(/ 100,000$ people/yr $)$. Over $65 y .0$. includes 65 years old.

$100,000 /$ year. Therefore, the total incidence of CSH will be $16.3(=13.7+2.6)$ per $100,000 /$ year in Japan in 2020.

\section{Discussion}

The epidemiological study of Awaji Island shows that the incidence of $\mathrm{CSH}$ was lower in the yellow areas, compared with other areas. Although our neurosurgical service covers the whole island, people in these areas facing Kobe or Tokushima areas, may consult with other clinics in these areas, because of easy access. Pcople in the pink and green areas are more likely, therefore, to form a representative sample. The pink areas had a much higher incidence of $\mathrm{CSH}$ in the elderly than the green areas. Two reasons may be considered: age distribution and environment. The elderly are $15.8 \%$ of all inhabitants in the green areas, but $21.4 \%$ in the pink areas. Furthermore, the pink areas are mountainous and the green areas flat plains. People in the pink areas, therefore, have more opportunities for accidents than people in the green areas.

Very few papers discuss the incidences of CSH (Table 1). Fogelholm et al. ${ }^{1)}$ reported 1.72 per $100,000 /$ year in all people and 7.4 per 100,000/year in people over 70 years old in Helsinki. Weber ${ }^{3)}$ reported 1 or 2 per 100,000/year in all people in Switzerland in 1968. The incidences in our series are much higher than in the Helsinki and Switzerland series. The mean incidences for the whole island were 13.1 per $100,000 /$ year in all people, 3.4 per $100,000 /$ year in people under 65 years old, and 58.1 per $100,000 /$ year in the elderly. At present, the elderly are $17.7 \%$ of the entire population of Awaji Island.

In Japan, the elderly will account for $23.6 \%$ of the population in $2020 .{ }^{2)}$ If the incidence of $\mathrm{CSH}$ on Awaji Island can be extrapolated to Japan in 2020, the incidence of $\mathrm{CSH}$ in the elderly will be approxi-

Table 1 Summary of incidences

\begin{tabular}{|c|c|c|c|c|}
\hline \multirow{2}{*}{ Place (Year) } & \multirow{2}{*}{$\begin{array}{c}\text { Ratio of } \\
\text { the elderly } \\
(\geqq 65 y .0 .)(\%)\end{array}$} & \multicolumn{3}{|c|}{ Incidence $(/ 100,000$ people $/ y r)$} \\
\hline & & $<65$ y.o. & $\geqq 65 y .0$ & All people \\
\hline $\begin{array}{l}\text { Switzerland } \\
(1968)^{3 !}\end{array}$ & - & - & - & 1 or 2 \\
\hline Helsinki $(1975)^{1\}}$ & - & - & 7.4 & 1.72 \\
\hline $\begin{array}{l}\text { Sumoto city } \\
(1988)^{*}\end{array}$ & $15.8^{* *}$ & 3.6 & 61.5 & 12.7 \\
\hline $\begin{array}{l}\text { Goshiki and } \\
\text { Ichinomiya } \\
\text { towns }(1988)^{*}\end{array}$ & 21.4 & 2.1 & 150.8 & 34.0 \\
\hline $\begin{array}{l}\text { Whole Awaji } \\
\text { lsland }(1988)^{*}\end{array}$ & 17.7 & 3.4 & 58.1 & 13.1 \\
\hline $\operatorname{Japan}(2020)^{2)}$ & 23.6 & (3.4) & $(58.1)$ & $16.3^{*}$ \\
\hline
\end{tabular}

*Present study. **Mear value in Sumoto city and Tsuna, Midori, and Mihara towns. $\$ 70-79$ years old. y.o.: years old. 
mately 13.7 per $100,000 /$ year and the total incidence will be 16.3 per $100,000 /$ year. However, these figures may not be accurate, because the yellow areas are included in these calculations. If the yellow areas are excluded, the incidence of $\mathrm{CSH}$ will be much higher. However, the approximate data indicate that CSH will become more frequent and may be the most common neurosurgical condition.

\section{References}

1) Fogelholm R, Heiskanen O, Waltimo O: Chronic sub- dural hematoma in adults. Influence of patient's age on symptoms, signs, and thickness of hematoma. $J$ Neurosurg 42: 43-46, 1975

2) Jinkou Seitai: Kokumin Eisei No Doukou. Tokyo, 1989, pp 42-47 (in Japanese)

3) Weber G: Das chronishe Subduralhematom. Schweiz Med Wschr 99: 1483-1488, 1969

Address reprint requests to: H. Kudo, M.D., Department of Neurosurgery, Rokko Island Hospital, 6-11 Naka, Koyo-cho, Higashinada-ku, Kobe 658, Japan. 